\title{
Dicer is required for Sertoli cell function and survival
}

\author{
GWANG-JIN KIM ${ }^{1,2, \#, ~ I N A ~ G E O R G ~}{ }^{1,2, \#, ~ H A R R Y ~ S C H E R T H A N ~}{ }^{3}$, MATTHIAS MERKENSCHLAGER ${ }^{4}$, \\ FLORIAN GUILLOU ${ }^{5}$, GERD SCHERER ${ }^{*, 1}$ and FRANCISCO BARRIONUEVO*,1 \\ ${ }^{1}$ Institute of Human Genetics, University of Freiburg, Germany, ${ }^{2}$ Faculty for Biology, University of Freiburg, \\ Germany, ${ }^{3}$ Bundeswehr Institute of Radiobiology, Munich, and MPI for Molecular Genetics, Berlin, Ger- \\ many, ${ }^{4}$ Lymphocyte Development Group, MRC Clinical Sciences Centre, Imperial College London, UK and \\ ${ }^{5}$ UMR 6175, Physiologie de la Reproduction, INRA-CNRS, Université de Tours, Nouzilly, France
}

\begin{abstract}
Dicer is a key enzyme that processes microRNA precursors into their mature form, enabling them to regulate gene expression. Dicer null mutants die before gastrulation. To study Dicer function in testis development, we crossed mice carrying a conditional Dicer allele with an $A M H$-Cre transgenic line, thereby inactivating Dicer in Sertoli cells around embryonic day 14.0 (E14.0). Dicer null Sertoli cells show normal embryonic development, and at postnatal day 0 (P0), testis tubules are normal in number and histologically undistinguishable from controls. Subsequently, Dicer-mutant testes show a progressively aberrant development, so that at P6, they contain a reduced number of disorganized testis tubules leading to primary sterility. Apoptosis and prophase $I$ assays reveal a massive wave of apoptosis starting at $P 3$, causing progressive loss of Sertoli cells, but also of germ cells, resulting in drastically reduced testis size. Expression of genes that play crucial roles in testis development, structural integrity and spermatogenesis is downregulated at PO, before morphological changes become apparent, indicating that Dicer-mutant testes are already transcriptionally compromised at this stage. Taken together, the results of this study show that Dicer is required for Sertoli cell function and survival and for spermatogenesis in mice.
\end{abstract}

KEY WORDS: Dicer, miRNAs, testis, spermatogenesis, sterility

\section{Introduction}

Sertoli cells, the somatic, epithelial cells of the testis cords and seminiferous tubules, play central roles during testis development (Wilhelm et al. 2007). They are formed shortly after the sex determination stage at embryonic day 11.5 (E11.5), when expression of the testis-determining gene Sryin pre-Sertoli cells of the $X Y$ gonad causes upregulation of expression of Sox9, which initiates a genetic cascade leading to the differentiation of preSertoli into Sertoli cells (Sekido and Lovell-Badge, 2008). During embryonic and fetal development, Sertoli cells are necessary for the formation and integrity of the germ cell-containing testis cords. They are also involved in the degeneration of the Müllerian ducts, the precursors of the female internal genitalia, through the action of the Sertoli cell-secreted factor anti-Müllerian Hormone, $\mathrm{AMH}$, and in the correct differentiation of the interstitial Leydig cells, which secrete testosterone to promote the differentiation of the Wolffian ducts into the male internal genitalia. Inactivating Sox9 before E11.5 in XY mice inhibits the formation of Sertoli cells and leads to the development of ovaries in place of testes (Chaboissier et al. 2004; Barrionuevo et al. 2006). Deletion of Sertoli cellspecific genes Wt1 (Gao et al. 2006) and Sox9 together with Sox8 (Barrionuevo et al. 2009) at around E14.0, shortly after testis cord formation, causes a wide spectrum of testis abnormalities including loss of testis cord architecture, maintenance of a rudimentary uterus and collapse of the testis resulting in sterility. At puberty, Sertoli cells undergo a process called maturation by which they

\footnotetext{
Abbreviations used in this paper: AMH, anti-Müllerian hormone; En, embryonic day n; EYFP, enhanced yellow fluorescent protein; PLZF, promyelocytic leukemia zinc finger protein; Pn, postnatal day $n$.
}

\footnotetext{
*Address correspondence to: Dr. Francisco Barrionuevo. Institute of Human Genetics, Breisacherstr. 33 , D-79106 Freiburg, Germany.

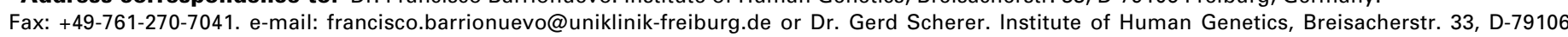
Freiburg, Germany. Fax: +49-761-270-7041. e-mail: gerd.scherer@uniklinik-freiburg.de \#Note: These authors contributed equally to this work
}

Supplementary Material for this paper (five additional figures) is available at: http://dx.doi.org/10.1387/ijdb.092874gk 
A
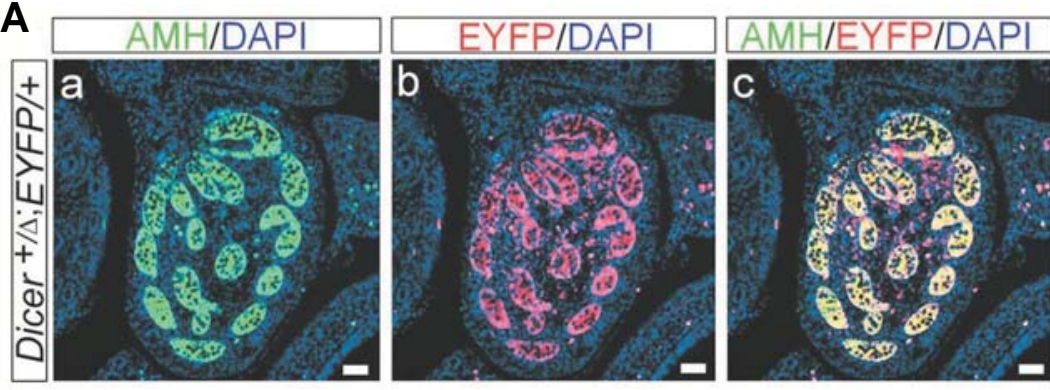

B

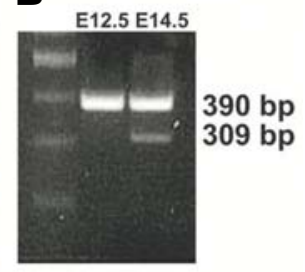

Fig. 1. Cre activity and Dicer inactivation. (A) Double immunostaining for the Sertoli cell marker AMH (green) (a) and for EYFP (red) (b) on E15.5 AMH-Cre;Dicer+/flox;EYFP/+ testes revealed co-localization of both signals in all Sertoli cells (overlay) (c). Note that red signals in $(b, c)$ outside testis cords are due to autofluorescence from Leydig cells and blood cells. (B) PCR using genomic DNA of entire AMHCre;Dicerflox/flox testes with primers that give a 390 bp or 309 bp product specific for the undeleted or deleted Dicer flox allele, respectively, produced a 309 bp fragment at E14.5 but not at E12.5, indicating that the onset of recombination occurs between these stages. Scale bar, $100 \mu \mathrm{m}$ (a-c).

Chen etal.2008; De Pietri Tonelli et al. 2008; and references therein). In the testis, Dicer has recently been conditionally inactivated in primordial germ cells (PGCs), resulting in impaired proliferation of spermatogonia (Hayashi et al. 2008).

In the present study, we triggered loss of Dicer in Sertoli cells after the sex determination stage by crossing mice carrying a Dicerflox allele (Cobb etal.2005) with an $\mathrm{AMH}-\mathrm{Cre}$ transgenic mouse line. This line expresses Cre under the control of the human $A M H$ promoter beginning at around E14.0 (Lécureuil et al.

change their morphology and function and establish the blood testis barrier, enabling them to support spermatogenesis. Failure in Sertoli cell maturation causes disorders in spermatogenesis (reviewed in Sharpe et al. 2003).

MicroRNAs (miRNAs) are a class of endogenous, noncoding RNAs that negatively regulate protein expression by either mRNA degradation or translational inhibition. The RNase III enzyme Dicer is required for the processing of the 21-22 nucleotides-short miRNAs and small interfering RNAs (siRNAs) from doublestranded RNA precursors (Bartel, 2004). Dicer-generated mature miRNAs are incorporated into the effector RNA-induced silencing complex (RISC) that triggers the destruction of complementary mRNAs or prevents their translation. Several studies have shown testis-specific expression of a number of miRNAs (Ro et al. 2007; Yan et al. 2007) and of components of the RNA interference machinery (Drosha, Dicer, Ago1-4) (Gonzalez-Gonzalez et al. 2008 ), indicating that they may play a role during testis development. Dicer-null mice die at E7.5 (Bernstein et al. 2003), preventing the study of the role that Dicermay play at later stages of development or in adult tissues. A way to bypass this early lethality consists in the generation of mice harbouring a conditional Dicer allele, Dicertlox, together with a tissue-specifically expressed Creallele. By means of this approach, Dicer has been inactivated in a number of discrete tissues (Cobb et al. 2005;
2002). The resulting testes with Dicer null Sertoli cells show normal embryonic development, and at P0, testis cords are normal in number and histologically undistinguishable from controls. Subsequently, Dicer-mutant testes show a progressively aberrant development, so that at P6, they contain a reduced number of disorganized testis cords where Sertoli and germ cells undergo apoptosis. We also find that spermatogenesis is arrested in the surviving testis cords, explaining why Dicernull mice are infertile.

\section{Results}

\section{Sertoli cell-specific ablation of Dicer}

To conditionally inactivate Dicerin Sertoli cells, we crossed mice with a floxed allele of Dicer (Dicerflox) to mice carrying the Sertoli cell-expressed $\mathrm{AMH}$-Cre transgene (Cobb et al. 2005; Lécureuil et al. 2002). To confirm Sertoli cell-specific ablation of floxed alleles by the $A M H$-Cre transgene, we crossed $A M H$ Cre,Dicerfloxfllox mice to mice harbouring the Cre reporter allele R26R-EYFP. Double immunohistochemistry for AMH, a Sertoli cell marker, and for EYFP on sections of E15.5 AMH-Cre;Dicert/ flox $: E Y F P /+$ testes revealed Cre-mediated recombination of the R26R-EYFP allele in all Sertoli cells (Fig. 1A). The onset of recombination of the Dicerflox allele in AMH-Cre;Dicerfloxfflox
A

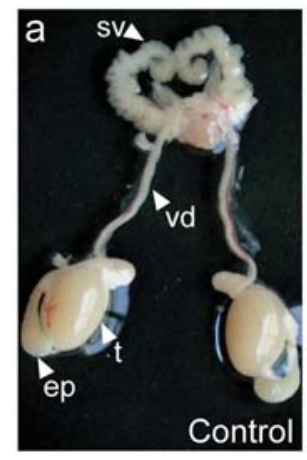

B

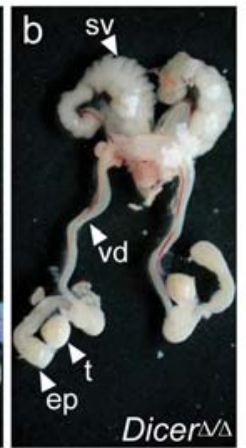

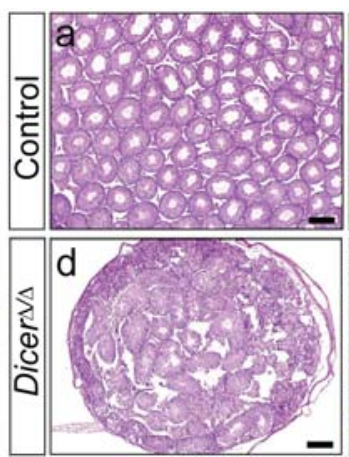

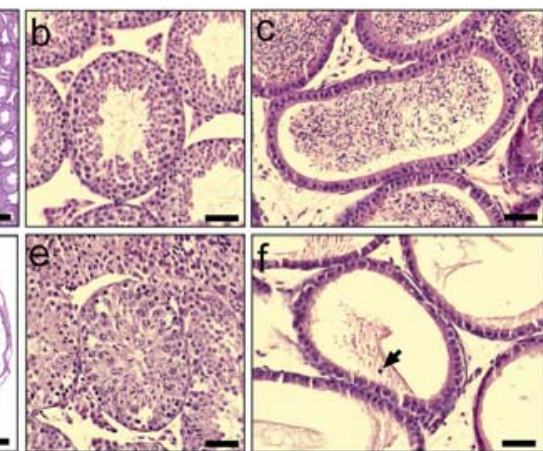

Fig. 2. Gonadal phenotype of Dicer $^{\Delta / \Delta}$ testes at 2 months. (A) Mutant males had normal appearance of the seminal vesicle, vas deferens and epididymis, but testes were severely reduced in size compared to controls. (B) Hematoxylin/eosin-stained sections. Mutant testes were significantly reduced in size, with testis tubules less densely packed compared to controls $(a, d)$. Higher magnification shows well-devel-

oped control tubules full of sperm (b) and mutant testis tubules with a disorganized epithelium and with no lumen and sperm (e). Control epididymides were full of mature sperm (c), whereas mutant epididymides were devoid of mature sperm (f). Occasionally, exfoliated germ cells were visible in mutant epididymides (f, arrow). Ep, epididymis; sv, seminal vesicle; $t$, testis; vd, vas deferens. Scale bar, $200 \mu m(a, d) ; 50 \mu m(b, c, e, f)$. 
(hereafter designated Dicer ${ }^{\mathrm{A} / \Delta}$ ) testes occurs around E14.0, as the 309 bp PCR product specific for the recombined Dicerflox allele was undetectable at E12.5, but was clearly detectable at E14.5 (Fig 1B). The 390 bp PCR product diagnostic for the nonrecombined Dicefflox allele at E14.5 derives from non-Sertoli cells, as DNA from whole testis was used for PCR. The time point of Cre action at around E14.0 is consistent with previous reports in which the $A M H$-Cretransgene has been used for the conditional deletion of other genes in embryonic Sertoli cells (Lécureuil et al. 2002; Gao et al. 2006; Chang et al. 2008; Barrionuevo et al. 2009).

\section{Gonadal phenotype of $\operatorname{Dicer}^{\Delta / \Delta}$ males at 2 months}

Dicer $^{\Delta / \Delta}$ mutant males were viable and showed normal external genitalia but they were sterile as no offspring was obtained when crossed to fertile wildtype females. Analysis of the urogenital tract of Dicer $^{\Delta / \Delta}$ males at 2 months revealed normal appearance of the seminal vesicles, vasa deferentia and epididymides. In contrast, mutant testes were significantly reduced in size when compared to controls (Fig. 2A). Histologically, mutant testes at 2 months were severely fibrotic, and the few remaining testis tubules were less densely packed compared to the testis tubules in the control littermates (Fig. 2B a,d). Most mutant testis tubules had no lumen and were devoid of mature sperm (Fig. 2Be). Accordingly, no mature sperm was found in the epididymides of mutant males, but occasionally, exfoliated germ cells were visible (Fig. 2Bf, arrow).

\section{Early postnatal abnormalities of Dicer $^{\Delta / \Delta}$ testis tubules}

To identify the time point at which testis development in Dicer ${ }^{\Delta / \Delta}$ males derails, we analysed the histology of the mutant gonads during early postnatal development and up to 1 months. At P0, no appreciable difference existed between control and mutant testis tubules (Fig. 3 A,B). But as early as at P3, mutant testis tubules were not as clearly developed as controls, with more interstitial space (Fig. 3 C,D). At P6, mutant testes were smaller than control testes and contained tubules that appeared disorganized and fibrotic (Fig. $3 \mathrm{E}-\mathrm{H})$. The situation was similar at P12, but notably, mutant tubules lacked the central lumen visible at this stage in the control testis tubules (Fig. 3 I,J). At 1 month, mutant testes were much smaller than control testes (Fig. $3 \mathrm{~K}, \mathrm{~L}$ ), but appeared more closely packed with testis tubules than at P12 (compare Fig. $3 \mathrm{~J}$ with L). Mutant tubules showed a wide range of anomalies, including tubules with a very reduced size, tubules formed only by Sertoli cells, and tubules lacking the central lumen; no mature sperm was visible in any of these tubules (Fig. $3 \mathrm{M}, \mathrm{N}$ ).

\section{Abnormal development of Sertoli cells in $\operatorname{Dicer}^{\Delta / \Delta}$ testes}

To trace the development of Sertoli cells in Dicer ${ }^{\Delta / \Delta}$ testes, we performed IHC for the Sertoli cell marker SOX9. During all stages analysed, Sertoli cells in control testes were located at the periphery of the testis tubules (Fig. 4 A-E). At P0, mutant Sertoli cells were all located at the periphery of the testis tubules (Fig. 4F). At P3, mutant Sertoli cells were mainly located at the periphery, but some cells were also located in the center of the tubules (Fig. 4G, arrow). In contrast, P6 mutant Sertoli cells, which displayed a somewhat less intense and variable SOX9 staining, were mainly located in the center of testis tubules (Fig. 4H), as was also the case for P12 mutant Sertoli cells (Fig. 4I). However, at 1 month, mutant Sertoli cells showed uniform SOX9 staining and were located at the periphery of the testis tubules in the same pattern as control Sertoli cells (Fig. $4 \mathrm{E}, \mathrm{J}$ ). The same results were obtained by IHC for
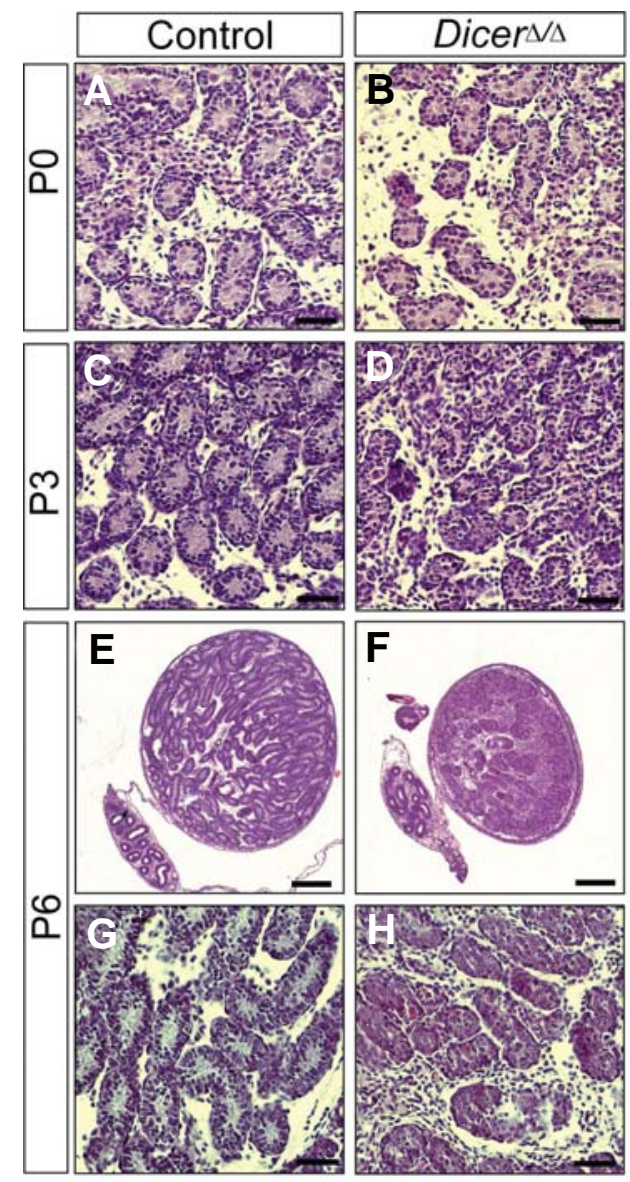
displayed a reduction in the number of testis tubules relative to testis size $(\mathbf{E}, \mathbf{F})$. High magnification reveals disorganized and fibrotic mutant testis tubules $\mathbf{( G , H ) . ~ A ~ s i m i l a r ~ s i t u a t i o n ~ w a s ~ f o u n d ~ a t ~ P 1 2 ~ ( I , J ) . ~}$ At 1 month, mutant testes were significantly reduced in size, with testis tubules less densely packed compared to controls $\mathbf{( K , L ) . ~ H i g h e r ~ m a g n i f i c a t i o n ~ r e v e a l s ~ a ~ w i d e ~ r a n g e ~ o f ~ a n o m a l i e s , ~ i n c l u d i n g ~ t u b u l e s ~}$ with a very reduced size (arrowhead), tubules formed only by Sertoli cells (asterisk), and tubules lacking the central lumen (star) (M,N). Scale bar, $50 \mu \mathrm{m}(A-D, G, H, M, N) ; 200 \mu \mathrm{m}(E, F, K, L) ; 100 \mu \mathrm{m}(I, J)$. 

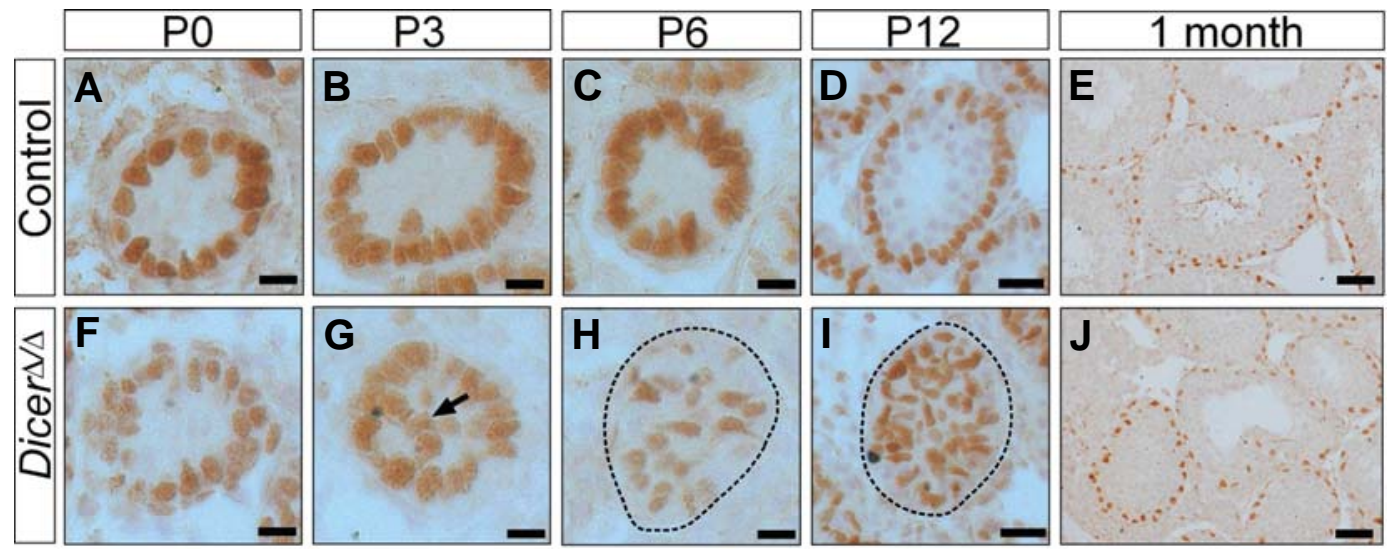

Fig. 4. Abnormal postnatal development of Sertoli cells in Dicer $\mathbf{S}^{/ \Delta}$ testes. IHC for the Sertoli cell marker SOX9. At all stages analysed, Sertoli cells were located at the periphery of control testis tubules (A-E). PO mutant Sertoli cells were located at the periphery (F). P3 mutant Sertoli cells were mainly found at the periphery, but also in the center of the tubules (G, arrow). Mutant Sertoli cells showed non-uniform SOX9 staining and were mainly located in the center of the tubules at P6 (H), and also at P12 (I). At 1 month, mutant Sertoli cells were located at the periphery of the testis tubules in the same pattern as control Sertoli cells (E,J). Scale bar, $10 \mu \mathrm{m}(A-C, F-H) ; 20 \mu \mathrm{m}(D, I) ; 50 \mu m(E, J)$.

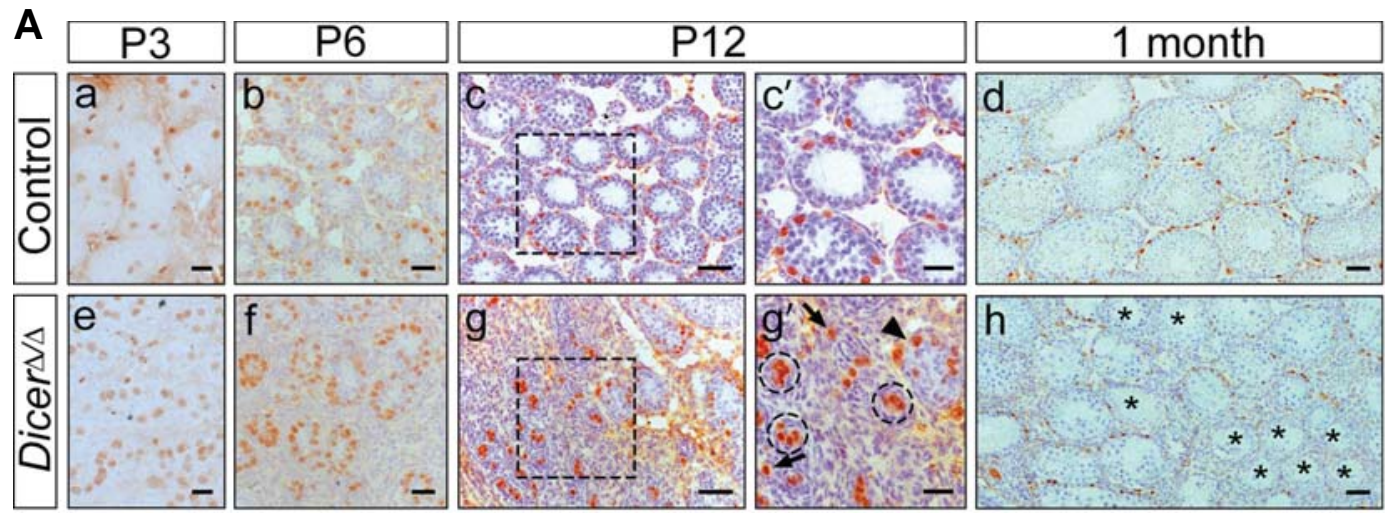

B
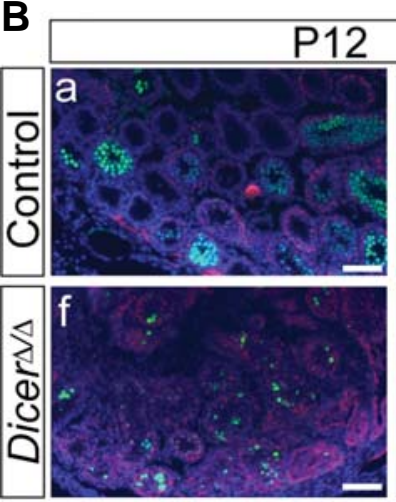
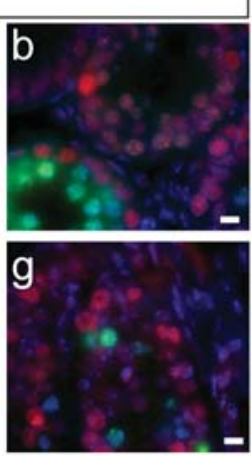
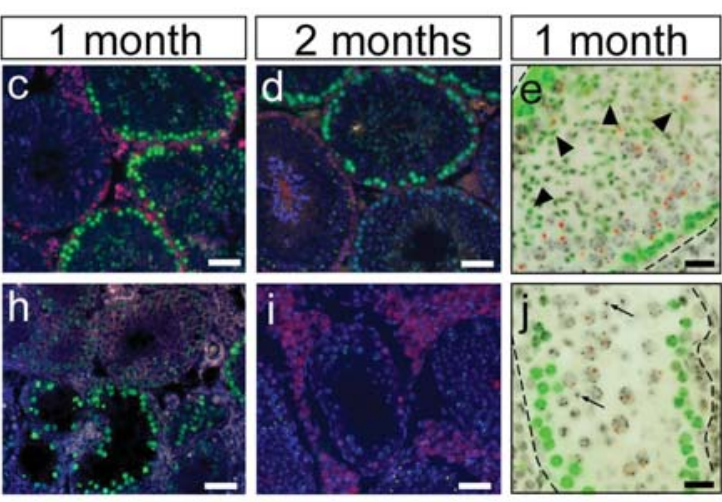

Fig. 5. Spermatogenesis arrests in Dicer $^{\Delta / \Delta}$ testes. (A) $I H C$ for $P L Z F$. At P3, PLZF expression was similar in control and mutant testis tubules (a,e). PLZF-positive cells were located at the periphery of control testis tubules at P6, P12 and 1 month $(b-d)$. P6 mutant testis tubules displayed a wildtype pattern of PLZF-positive cells (f). At P12, mutant testes contained tubules with a normal pattern of expression ( $g$ ', arrowhead), clusters of stained cells surrounded by peritubular myoid cells $\left(g^{\prime}\right.$, dashed circles), and single positive cells outside of the tubules ( $g^{\prime}$, arrows). At 1 month, some tubules showed a normal PLZF expression pattern, while other tubules were completely devoid of PLZF-positive cells (h, asterisks). (c', $g^{\prime}$ ) Enlargements of the areas boxed in $(c, g)$. (B) Immunofluorescence for $\gamma$-H2AX (green), p53BP1 (red), Mre11 (red in $e, j)$ and DNA (DAPI, blue lgrey in $e, j])$ in control $(a-e)$ and Dicer ${ }^{\Delta / \Delta}$ testes (f-j). Spermatogonia and Sertoli cells show red nuclear p53BP1 labelling at $P 12(a, b, f, g)$. Synchronous onset of spermatogenesis at P12 as indicated by $\gamma$-H2AX-positive leptotene spermatocytes filling the tubules in the wildtype (a, b). A low number of $\gamma$-H2AX-positive leptotene spermatocytes marks an asynchronous and delayed onset of spermatogenesis in the P12 Dicer-mutant (f, $g$ ). This phenotype was also seen after DMC1 staining (Suppl. Fig. S4). One and two month-old control testes showing ordered progression of spermatogenesis with $\gamma$-H2AX-bright (green) peritubular leptotene spermatocytes and dimly green stained elongating spermatids in stage IX-X tubules $(c, d)$. Section of a 1 month-old mutant testis showing absence of multi-layered epithelium in several tubules (lower left) that display $\gamma$-H2AX-bright leptotene spermatocytes (green) (h). Section of a 2 month-old mutant tubule displaying a few peritubular pachytene spermatocytes whose nuclei feature a $\gamma$-H2AX-positive $X Y$ body (green dot) while spermatids are absent; large p53BP1-positive (reddish) fibrotic tissue separates the tubules (i). $(e, j)$ Stage IX-X tubule from 1 month-old control and mutant testes displaying peripheral $\gamma$-H2AX-bright leptotene spermatocytes (green) and pachytene spermatocytes each with a reddish dot that represents the Mre11 (red)-and $\gamma$-H2AX (green) -positive XY body (see Barchi et al. 2005). Dimly $\gamma$-H2AXpositive elongated spermatids are present in the control tubule (e, arrowheads), while the mutant tubule contains a few round spermatids only ( $j$, arrows). Note that DAPI staining in (e,j) is colour inverted to gray scale for better visualization. Scale bar, $20 \mu \mathrm{m}$ (Aa,b,e,f); $25 \mu \mathrm{m}\left(\mathrm{Ac} \mathrm{c}^{\prime}, \mathrm{g}\right.$ ); $50 \mu \mathrm{m}$ $(A c, d, g, h) ; 100 \mu m(B a, f) ; 10 \mu m(B b, g) ; 50 \mu m(B c, d, h, i) ; 20 \mu m(B, e, j)$. 
WT1, another Sertoli cell marker (data not shown). That Cre recombinase had successfully acted in all mutant Sertoli cells was demonstrated by IHC for EYFP in 1 month old Dicer ${ }^{\mathrm{S} /} ;$ EYFP $^{-}+$ mutant testes (Supplementary Fig. S1). Taken together, these results indicate that Sertoli cells follow an aberrant developmental program between P3 and P12 in Dicer-mutant testis tubules, but they subsequently manage to organize in the correct manner at the periphery within the few remaining tubules.

\section{Spermatogenesis arrests in $\operatorname{Dicer}^{\Delta / \Delta}$ testes}

To follow the development of germ cells, we performed IHC for PLZF, a marker for gonocytes at the early stages of testis development, and for spermatogonial stem cells (SSCs) after the onset of meiosis (Buaas et al. 2004). At P3, we observed the same pattern of PLZF expression in both control and mutant testis tubules (Fig. 5A a,e). As to be expected for SSCs, PLZFpositive cells were located at the periphery of control testis tubules from P6 onwards (Fig. 5A b-d). PLZF-positive cells were also present at the periphery of mutant testis tubules at P6 (Fig. 5Af). At P12, some mutant tubules showed a normal pattern of expression, but there were also clusters of PLZFexpressing cells surrounded by peritubular myoid cells and single positive cells outside of the tubules (Fig. 5A g, $\mathrm{g}^{\prime}$ ). At 1 month, approximately half of the mutant tubules displayed a normal PLZF staining pattern, whereas the remaining tubules were completely devoid of PLZF-positive cells (Fig. 5Ah). The number of PLZF-positive cells was determined in six control and six mutant testes, revealing a non-significant two-fold and significant five-fold decrease $(P<0.01)$ at $\mathrm{P} 6$ and $\mathrm{P} 12$, respectively, per total testis volume in the mutant (Supplementary Fig. S2). As SSCs and undifferentiated spermatogonia in neonatal testis coexpress OCT4 together with PLZF (Filipponi et al. 2007), the same stages shown in Fig. 5A were also analyzed by IHC for OCT4. The results were similar to PLZF: mutant tubules showed normal OCT4 expression pattern up to P6, more mutant tubules than in control were OCT4-negative and some contained OCT4-positive cells away from the periphery at P12, while only very few mutant tubules remained OCT4-positive at 1 month (Supplementary Fig. S3). Altogether, these data indicate that, starting at $\mathrm{P} 6$, there is a progressive loss of spermatogonial stem cells in Dicer ${ }^{\Delta / \Delta}$ testes.

We next analysed the onset and progression of spermatogenesis in control and mutant testes by immunofluorescence for the DNA repair protein markers $\mathrm{p} 53 \mathrm{BP} 1$, Mre11 and $\gamma-\mathrm{H} 2 \mathrm{AX}$ (Fig. 5B). p53BP1 is a marker for non-homologous end-joining DNA repair that is strongly expressed in nuclei of Sertoli cells, intertubular cells and spermatogonia (Ahmed et al. 2007). Leptotene and zygotene spermatocyte nuclei strongly express phosphorylated $\mathrm{H} 2 \mathrm{AX}(\gamma-\mathrm{H} 2 \mathrm{AX})$ histones, pachytene spermatocytes show a $\gamma-\mathrm{H} 2 \mathrm{AX}$ - and Mre11-positive $\mathrm{XY}$ body (Barchi et al. 2005), while elongating spermatids show a diffuse $\gamma$-H2AX nuclear signal corresponding to chromatin remodelling and associated DNA double strand break formation that occurs during sperm head condensation (Meyer-Ficca et al. 2005). At $\mathrm{P} 12$, in control and Dicer-mutant testes, Sertoli cells and spermatogonia were positive for p53BP1 (Fig. 5B a,b,f,g). Numerous control tubules displayed characteristic $\gamma$-H2AX-positive prophase I stages that filled the tubule lumina (Fig. 5B a,b), while most mutant tubules showed a highly asynchronous onset of spermatogenesis, with only a few $\gamma$-H2AX-bright leptotene and zygotene spermatocytes (Fig. 5B f,g). These results were confirmed by the reduced expression of the prophase Ispecific DMC1 recombinase in the mutant (Supplementary Fig. S4). At 1 and 2 months, there was normal spermatogenesis in the control (Fig. 5B c-e). Dicer-mutant testes at 1 month contained many empty tubules and some stage IX-X tubules that displayed only a peritubular layer of $\gamma-\mathrm{H} 2 \mathrm{AX}$-positive leptotene spermatocytes, while subsequent stages were missing (Fig. 5Bh). Other stage IX-X mutant tubules at 1 month con-
A

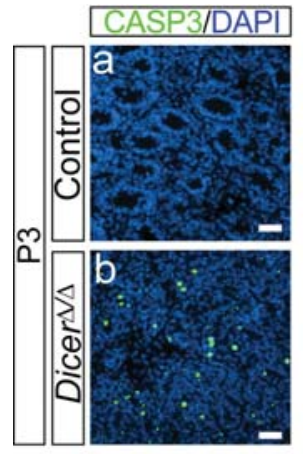

C

Apoptotic cells in testis cords

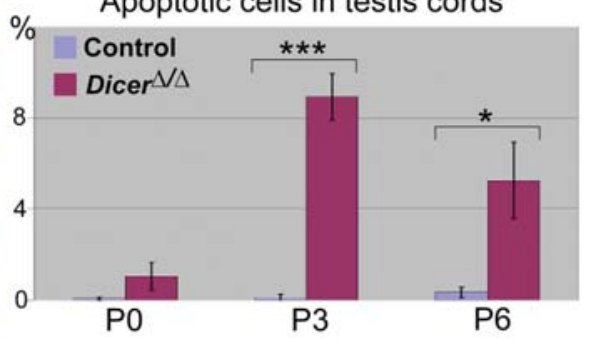

B

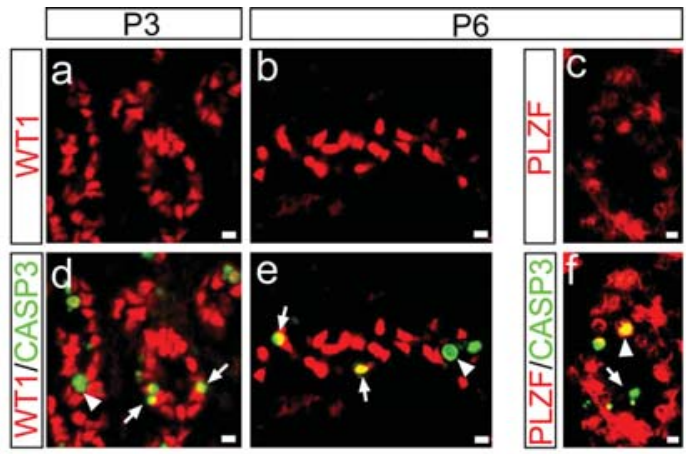

C

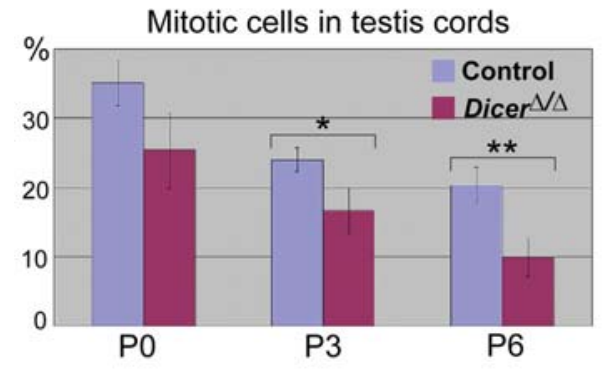

Fig. 6. Sertoli cell apoptosis in early postnatal Dicer $\mathbf{\Delta}^{\mathbf{\Delta} \Delta}$ testes. (A) Anti-activated Caspase3 immunofluorescence revealed high numbers of apoptotic cells in mutant testis tubules at P3 (a,b). Quantification of apoptotic cells (c). (B) Single (a-c) and double immunofluorescence (d-f) for the Sertoli cell marker WT1 or the germ cell marker PLZF (both in red) and for activated Caspase3 (green) in P3 and P6 mutant testis tubules. Caspase3-positive cells positive or negative for WT1 indicate dying Sertoli cells (arrows) or dying germ cells (arrowhead), respectively (d,e). Caspase3-positive cells positive or negative for PLZF indicate dying germ cells (arrowhead) or dying Sertoli cells (arrow), respectively (f). (C) H3P staining revealed no significant difference in cell proliferation between control and mutant testes at PO, but at P3 and P6. Scale bar, $50 \mu \mathrm{m}$ (Aa,b); 10 $\mu \mathrm{m}(\mathrm{Ba}-\mathrm{f})$. 
tained spermatocytes and round spermatids (Fig. 5Bj, arrows) but elongating spermatids, as normally seen in wildtype IX-X tubules (Fig. 5Be, arrowheads), were mostly absent. Two month-old mutant testes showed the same phenotype as at 1 month (Fig. 5Bi). One or 2 month-old mutant testes only rarely contained elongating spermatids (Supplementary Fig. S5). Like the wildtype (Barchi et al. 2005), mutant pachytene spermatocytes displayed a $\gamma$-H2AX and Mre11-positive XY body (Fig. 5B $\mathrm{e}, \mathrm{j}$ ), indicating that sex chromosome pairing and silencing occurred normally in those mutant cells that reached pachytene. Together, these data document an early and progressive defect in spermatogenesis in the mutant testes.

\section{Sertoli and germ cell apoptosis in early postnatal Dicer ${ }^{\Delta / \Delta}$ testes}

Since Dicer ${ }^{\Delta / \Delta}$ mutants appear to lose both Sertoli and germ cells, we next examined whether the mutant testis tubules may degenerate via apoptosis. Immunostaining for activated Caspase3 showed a high number of apoptotic cells throughout the mutant testes at P3 (Fig. 6Ab). Counting of apoptotic cells revealed that apoptosis starts after P0, peaks at P3, and declines at P6 (Fig. $6 \mathrm{Ac}$ ). These results are consistent with the progressive degradation of the mutant testes observed at the histological level. To identify the nature of apoptotic cells, we next performed double immunostaining for WT1, a Sertoli cell marker, and for activated Caspase3. At P3, most Caspase3-positive cells were also positive for WT1 (Fig. 6Bd, arrows), indicating a significant Sertoli cell death at this stage. Ocassionally, we also detected a WT1negative, Caspase3-positive cell within the testis tubules (Fig. $6 \mathrm{Bd}$, arrowhead), indicating that some germ cells are also dying at this stage. The same situation was observed at P6, but at this stage, the Caspase 3 signal was found more equally distributed between WT1-positive and -negative cells (Fig. 6Be). Double IHC for the SSC marker PLZF and for activated Caspase3 confirmed that germ cells are indeed dying at P6 (Fig. 6Bf). Identical results were obtained if SOX9 was used as a Sertoli cell marker instead of WT1 (data not shown). When we analyzed proliferation by staining for phospho-histone $\mathrm{H} 3$, a marker for prometaphase and metaphase cells in mitosis and meiosis (Hendzel et al. 1997), we observed no significant difference between control and mutant testes at P0, but a significant decrease in cell proliferation in the mutant testes at P3 and P6 (Fig. 6C). Therefore, the progressive size difference between control and mutant testes and the eventual loss of testis tubules in mutant mice seems to be caused both by an increase in apoptosis and by a decrease in cell proliferation.

\section{Altered gene expression in $\operatorname{Dicer}^{\Delta / \Delta}$ testes at the newborn stage}

Real-time RT-PCR analyses were performed on testes from newborn mice, a stage where testicular histology of mutants appeared normal. We examined transcript levels of markers playing crucial roles in testis development and differentiation, spermatogenesis, and structural integrity (Table 1). Compared with control testes, we found that transcript levels of several important markers of Sertoli cells, such as Sox9, Sox8, Amh, Fgf9 and Dhh, were significantly downregulated in P0 mutant testes, except for $W t 1$, which was only slightly reduced. We also examined expression levels of genes for Sertoli cell-derived signalling molecules GDNF (glial cell line-derived neurotrophic factor) and
TABLE 1

\section{REAL-TIME PCR QUANTIFICATION OF GENE EXPRESSION CHANGES IN DICER ${ }^{V A}$ MUTANT TESTES AT PO}

\begin{tabular}{|c|c|c|c|}
\hline & $\operatorname{Dicer}^{\text {flox/flox }} ;+/+$ & Dicer $^{\Delta \Delta}$ & \\
\hline Sox9 & $1.01 \pm 0.06$ & $0.60 \pm 0.04$ & ** \\
\hline Sox8 & $1.02 \pm 0.09$ & $0.36 \pm 0.04$ & *** \\
\hline Amh & $1.00 \pm 0.01$ & $0.59 \pm 0.02$ & *** \\
\hline$W+1$ & $1.00 \pm 0.04$ & $0.86 \pm 0.04$ & * \\
\hline Fgf9 & $1.01 \pm 0.06$ & $0.55 \pm 0.05$ & *** \\
\hline Dhh & $1.01 \pm 0.05$ & $0.50 \pm 0.04$ & *** \\
\hline Gdnf & $1.00 \pm 0.03$ & $0.32 \pm 0.02$ & *** \\
\hline Fgf2 & $1.03 \pm 0.13$ & $0.73 \pm 0.04$ & \\
\hline$K I$ & $1.01 \pm 0.05$ & $0.62 \pm 0.04$ & *** \\
\hline Bmp4 & $1.03 \pm 0.05$ & $0.65 \pm 0.03$ & ** \\
\hline Connexin43 & $1.00 \pm 0.04$ & $0.39 \pm 0.02$ & *** \\
\hline Occludin & $1.00 \pm 0.05$ & $0.31 \pm 0.04$ & *** \\
\hline Claudin 11 & $1.01 \pm 0.07$ & $0.27 \pm 0.04$ & *** \\
\hline
\end{tabular}

Five pairs of control and mutant testes were used. Data are mean \pm s.e.m. $\left({ }^{*} P<0.05 ;{ }^{* *} P<0.01\right.$; $\left.{ }^{* * *} P<0.001\right)$.

FGF2, involved in SSC self-renewal and proliferation (Meng et al. 2000; Simon et al. 2007), and KL (Kit ligand) and BMP4, involved in SSC differentiation (Pellegrini et al. 2003, 2008). Whereas expression levels of Fgf2 were unchanged, $\mathrm{K} /$ and $\mathrm{Bmp} 4$ were downregulated by about $40 \%$ and $G d n f$ by about $70 \%$. Furthermore, transcript levels of Connexin43, which codes for a protein forming gap junctions between Sertoli cells and between Sertoli cells and germ cells, and of occludinand claudin 11, which encode tight junction proteins involved in the formation of the blood-testis barrier (Mruk and Cheng, 2004), are reduced by a similar degree as the Gdnftranscript levels (Table 1). All of this indicates that, in spite of their morphologically normal appearance, P0 mutant testes and Sertoli cells are already transcriptionally compromised.

\section{Discussion}

To assess the requirement of Dicer for the development of Sertoli cells and their relation to spermatogenesis, and to overcome the embryonic lethality associated with Dicernull mutants, we have deleted a floxed Dicerallele using an $A M H-C r e$ deleter strain. Inactivation of Dicer in Sertoli cells occurred at around E14.0 and subsequently led to a breakdown of spermatogenesis and a severe decrease in the number of testis tubules leading to primary infertility.

Morphologically, no difference between Dicer-ablated testes and control testes was apparent at birth. Thereafter, the development of mutant Dicer testes deviated from that of controls, showing a phenotype of spermatogenic failure that increased in severity with age. Concurrently, we found an increase in the number of apoptotic cells. The peak in the number of apoptotic cells was detected at P3, just prior to the beginning collapse of mutant testes at P6. Cell death is a common phenomenon associated with Dicerconditional knockouts (Chen et al. 2008; De Pietri Tonelli et al. 2008; and references therein). Additionally, in vitro studies have shown that downregulation of Dicer results in accelerated apoptosis (Matskevich etal.2008), and that antisenseinhibition of a number of miRNAs increased the level of apoptosis (Cheng etal. 2005). Dicer is also essential for the formation of the 
heterochromatin structure, and its loss results in cell death with the accumulation of abnormal mitotic cells that show premature sister chromatid separation (Fukagawa et al. 2004). In the light of these observations, it is conceivable that the increased apoptosis we oberved in Dicer-deficient Sertoli cells is the consequence either (i) of the downregulation of miRNAs essential for the regulation of the apoptotic pathway, or (ii) of the role of Dicerin establishment of differentiation-dependent heterochromatin marks, or (iii) of a combination of both. The question arises as to why significant apoptosis is occurring only at P3 and later, about nine days after the recombination of the Dicerflox allele. This could be explained by assuming that Sertoli cells change their gene expression profile during their development and that, as a consequence, they may become more dependent on miRNA-mediated regulation than at earlier stages. Indeed, at around puberty (P8P12), Sertoli cells undergo a process called maturation in which they change their morphology and function to support the first wave of spermatogenesis. Our results could indicate that shortly before this period, Sertoli cells become more dependent on miRNA-mediated control than at earlier stages. A similar situation has been described recently in neurogenic progenitor cells that were unaffected after Dicer ablation at the early stage of neurogenesis but underwent apoptosis at later stages (De Pietri Tonelli et al. 2008). This is in accordance with the view of Stark and coworkers (Stark et al. 2005) that microRNAs confer precision and robustness to developmental gene expression programs, thus ensuring tissue identity and supporting cell-lineage decisions.

Alternatively, the delay in the onset of Sertoli cell death and faulty development may be a consequence of long-term stability of miRNAs such that their levels start to decrease only after a lag phase of several days following Dicer inactivation. In fact, a preliminary analysis of all four of the several Sertoli cell-expressed miRNAs described by Ro and coworkers (Ro et al. 2007) indicates no significant change in mutant versus control testes at P0 (data not shown). Despite of this, we observed significant downregulation of essentially all Sertoli cell-expressed transcripts analysed already at P0. Thus, loss of Dicerfunction clearly has an early effect on the transcriptional competence of Sertoli cells that precedes morphologically apparent changes. Interestingly, Wt1 and Sox9, which were both downregulated, have previously been inactivated in a conditional manner using the same AMH-Cre transgene that we used in this study. In the case of $W t 1$, this resulted in the prenatal disruption of testis cords and progressive loss of Sertoli and germ cells (Gao et al. 2006), while in the case of Sox9, concomitant inactivation of Sox 8 caused postnatal failure of the differentiation of testis tubules into seminiferous tubules leading to complete primary infertility (Barrionuevo et al. 2009). Thus, the phenotype of the Dicer-mutants may partially be explained by the reduced expression of $W t 1$, Sox 9 and Sox 8 we observe at P0.

We also studied the expression of genes encoding molecules important for the structural integrity of the sex cords such as proteins involved in formation of Sertoli-Sertoli or Sertoli-germ cell contacts. Occludin and claudins are components of multiprotein complexes that form the tight junctions of mature Sertoli cells that constitute the blood-testis barrier. This barrier is essential for proper spermatogenesis, as males nullizygous for occludin or claudin 11 are sterile (Gow et al. 1999; Saitou et al. 2000). In
Dicer-mutant testes, mRNA levels were reduced by about $70 \%$ for occludin and claudin 11. Of the more than a dozen connexins found in testicular gap junctions, connexin 43 (CX43) is the best studied and is a component of Sertoli-Sertoli and Sertoli-germ cell gap junctions (Decrouy et al. 2004). Recently, a Sertoli cellspecific knockout of $C \times 43$ was shown to prevent the initiation of spermatogenesis (Brehm et al. 2007; Sridharan et al. 2007). Similar to occludin and claudin 11, Cx43 transcript levels were downregulated to about one third of the wildtype level in Dicer testes. These changes were all apparent at P0, prior to histologically detectable abnormalities. It thus seems possible that the primary spermatogenic failure displayed by the Dicer-mutant testes results in part also from the reduced expression of these three junctional molecules.

Despite the massive apoptosis within the testis tubules beginning at P3, some Dicer-mutant testis tubules survived. This allowed us to follow the development of these tubules during spermiogenesis and spermatogenesis. Monitoring the prophase I-specific pattern of p53BP1 and $\gamma$-H2AX expression (Meyer Ficca et al. 2005; Ahmed et al. 2007), as well as sex body formation in pachytene spermatocytes by $\gamma-\mathrm{H} 2 \mathrm{AX}$ and Mre 11 expression, we observed tubules where the seminiferous epithelium at stages IX -XI was disrupted beyond the leptotene spermatocyte layer. In tubules with an undisrupted epithelium, chromosome pairing at pachytene was normal as indicated by normal XY-body formation, but spermiogenesis was mostly arrested at the round spermatid stage, with elongated and elongating spermatids seen only rarely in mutant tubules. This indicates that in the majority of mutant tubules, loss of Dicercauses a block to the initiation of spermatid chromatin remodeling that occurs at the elongating spermatid steps (McPherson and Longo, 1993; Marcon and Boissonneault, 2004). In addition, the Dicer-mutant testes are loosing SSCs, which could be a consequence of the downregulation of $G d n f, K /$ and $B m p 4$, which all encode signalling molecules involved in SSC self-renewal and differentiation.

While this work was in progress, a report appeared that described the phenotype of a Sertoli cell-specific Dicerablation that involved the same $A M H$-Cre line used in our study but a different Dicer-flox allele (Papaioannou et al. 2009). Their data are in agreement with our results including the severe impairment of the prepubertal spermatogenic wave in Dicer-mutant testes due to development of defective Sertoli cells that fail to properly support meiosis and spermatogenesis, the massive Sertoli cell and germ cell apoptosis, and the transcriptional downregulation of major regulators of testicular development or spermatogenesis. They also describe numerous spermatogenic defects and progressive testis degeneration and note the almost complete absence of elongating spermatids in mutant tubules. While they observe increased apoptosis starting at P5, we show that this starts already at P3. Surprisingly, they measured increased proliferation of mutant Sertoli cells at P0, P5 and P15, whereas our study revealed a decrease in proliferation of cells in mutant testis tubules at P0, P3 and P6, which is consistent with decrease in cell proliferation frequently observed in other conditional Dicer ablation studies (Murchison et al. 2005; Hayashi et al. 2008; Kobayashi etal. 2008). While Papaoiannou et al. also noticed that mutant Sertoli cells mislocate towards the center of tubules around P5, they did not describe the phenomenon that they later relocate to the tubular periphery at 1 month, expressing SOX9 
stronger than they did at P6 (Fig. 4). As the Cre recombinase has recombined the $R 26 R$-EYFPCre reporter allele in all Sertoli cells of 1 month-old mutant tubules (Supplementary Fig. S1), it can be inferred that Diceris ablated completely in all Sertoli cells in the mutant. Why Dicernull Sertoli cells behave in this manner is not clear. Possibly, only those Sertoli cells survive up to 1 month where the loss of Dicerhad only a transitory effect. Interestingly, Murchison et al. (2005) observed after deletion of Dicerin embryonic stem cells that some of the mutant cells are able to overcome the initial defect in proliferation and survive ("escapers"), regaining the potential to establish stem cell lines.

In conclusion, our study shows that Dicerfunction in Sertoli cells is important for the regulation of the events that govern a synchronous onset of spermatogenesis and for the maintenance of a multilayered architecture of the seminiferous epithelium essential for spermatid differentiation.

\section{Materials and Methods}

\section{Mouse crosses}

Dicerfloxflox mice (Cobb et al. 2005) were bred to AMH-Cre mice (Lécureuil et al. 2002) on a C57BL/6 background, and the resulting $A M H$ Cre;Dicerflox/t offspring was backcrossed to Dicerflox/flox mice to obtain AMH-Cre;Dicerfloxflox mice. R26R-EYFPCre reporter mice (Srinivas et al. 2001) were kindly supplied by Frank Constantini. Primers and PCR conditions for genotyping were used as previously described (Lécureuil et al. 2002; Kobayashi et al. 2008). Primers to detect the 390 bp product diagnostic for the non-recombined Dicerflox allele and the 309 bp product diagnostic for the recombined Dicerfox allele were

5'-AGTGTAGCCTTAGCCATTTGC-3' and

5'-AGTAATGTGAGCAATAGTCCCAG-3', respectively, and were used together in a single $P C R$ reaction in combination with primer 5'-CTGGTGGCTTGAGGACAAGAC-3'.

\section{Histologic and immunohistochemical analysis}

For histology, embryos and dissected gonads were collected in PBS, fixed in Serra (ethanol:37\% formaldehyde:acetic acid, 6:3:1), embedded in paraffin, sectioned to $7 \mu \mathrm{m}$, and stained with hematoxylin and eosin. Immunostaining was performed using either the Vectastain ABC Kit or the Vector M.O.M. Immunodetection Kit (both from Vector Laboratories) following the manufacturer's guidelines. The following commercial antibodies were used: SOX9 (catalog no. sc-17341, dilution 1:100), AMH (sc6886, 1:100), and PLZF (sc-21389, 1:75) (all from Santa Cruz, CA); GFP (3999-100, 1:100, BioVision); $\gamma$-H2AX (05-636, 1:500, Biomol); p53BP1 (NB 100-304, 1:500, Acris Antibodies); Mre11 (1:200, Novus Biologicals), and WT1 (M3561, clone 6F-H2, 1:150, DAKO). Stained slides were examined with a Zeiss Axioskop 40 microscope. Images were captured by a Zeiss CCD camera. For immunofluorescence, anti-mouse-TRITC ( $T$ $7782,1: 200)$ and anti-rabbit-FITC (F 0382, 1:200) (both from Sigma) and anti-mouse-Cy2 and anti-rabbit-Cy3 antibodies (both from Dianova) were used. Fluorescent signals were recorded using a Zeiss Axioplan 2 fluorescence microscope equipped with the ISIS imaging system (MetaSystems). Sections of control and mutant gonads were always mounted on the same slide. At least three pairs of control and mutant gonads were analysed for each time point.

\section{Real-time RT-PCR}

Total RNA from P0 testes was extracted using the RNeasy Micro kit (Qiagen) including DNase I treatment. RNA integrity was checked with the Agilent 2100 Bioanalyzer (Agilent Technologies) and samples with an RIN above 9.0 were used. Synthesis of cDNA was performed using oligo dT primers and Superscript III reverse transcriptase (Invitrogen). PCR was performed using the QuantiTect SYBR green real-time PCR kit
(Qiagen). Each sample was measured in duplicate in at least two independent experiments. $\mathrm{C}_{\mathrm{T}}$ values of samples were normalized to the corresponding $\mathrm{C}_{\mathrm{T}}$ values of Gapdh, and relative expression levels were calculated by the $\Delta \Delta C_{\mathrm{T}}$ method (Livak and Schmittgen, 2001). Primer pairs used were:

Bmp4, 5'-AGGAGGAGGAGGAAGAGCAGAG-3' and 5'- TGAAGAGGAAACGAAAAGCAGA-3';

Fgf2, 5' -CAAACTACAACTCCAAGCAGAAGA-3' and

5'- CCAGTCGTTCAAAGAAGAAACAC-3';

KI, 5'-AGTAATAGGAAAGCCGCAAAGG-3' and

5' - CTCCAAAAGCAAAGCCAATTAC-3';

Primer pairs for all other transcripts are published (Barrionuevo et al. 2009; and references therein).

\section{Analysis of cell proliferation and cell death}

For cell proliferation, $7 \mu \mathrm{m}$ sections were stained with an anti-phosphohistone $\mathrm{H} 3$ antibody (Upstate, Cat 06-570, 1:200), and for detection of apoptotic cells, the anti-Caspase3-active antibody (R\&D Systems, Cat AF-835, 1:100) was used. Both primary antibodies were detected using the $A B C$ kit (Vector Laboratories, Burlingame, CA) following the manufacturer's protocol. The slides were counterstained with hematoxylin. For quantification, positive- and negative-staining cells in 30 randomly selected testis tubules per individuum were counted. For each time point and genotype, three different animals were examined. To obtain the percentage of positive cells in the tubules, the number of positive cells was set in relation to the total number of cells.

\section{Statistical Methods}

All values are expressed as the mean \pm s.e.m. Statistical analysis was performed by the Student's $t$ test, and results were considered statistically significant at a $P$ value $<0.05\left(^{*}\right),<0.01\left(^{(*}\right)$, and $<0.001\left(^{* * *}\right)$.

\section{Acknowledgements}

We thank Christoph Englert forkind gifts of antibodies, Frank Constantini for the R26R-EYFP Cre reporter line, Annika Fischer for help in cell counting, and Serge Nef for sharing unpublished information. This work was supported by grants from the Deutsche Forschungsgemeinschaft to G.S. (Sche 194/15-3, GRK1104).

\section{References}

AHMED EA, VAN DER VAART A, BARTEN A, KAL HB, CHEN J, LOU Z, MINTERDYKHOUSE K, BARTKOVA J, BARTEK J, DE BOER P, DE ROOIJ DG (2007). Differences in DNA double strand breaks repair in male germ cell types: lessons learned from a differential expression of Mdc1 and 53BP1. DNA Repair6: 12431254.

BARCHI M, MAHADEVAIAH S, DI GIACOMO M, BAUDAT F, DE ROOIJ DG, BURGOYNE PS, JASIN M, KEENEY S (2005). Surveillance of different recombination defects in mouse spermatocytes yields distinct responses despite elimination at an identical developmental stage. Mo/ Ce/l Bio/25: 7203-7215.

BARRIONUEVOF, BAGHERI-FAMS, KLATTIGJ, KISTR, TAKETO MM, ENGLERT C, SCHERER G (2006). Homozygous inactivation of Sox9causes complete XY sex reversal in mice. Biol Reprod 74: 195-201.

BARRIONUEVO F, GEORG I, SCHERTHAN H, LÉCUREUIL C, GUILLOU F, WEGNER M, SCHERER G (2009). Testis development after the sex determination stage is independent of Sox9 but fails in the combined absence of Sox9 and Sox8. Dev Bio/327: 301-312.

BARTEL D. (2004). MicroRNAs: genomics, biogenesis, mechanism and function. Cel/ 116: 281-297

BERNSTEIN E, KIM SY, CARMELL MA, MURCHISON EP, ALCORN H, LI MZ, MILLS AA, ELLEDGE SJ, ANDERSON KV, HANNON GJ (2003). Dicer is essential for mouse development. Nat Genet 35: 215-217.

BREHM R, ZEILER M, RUTTINGER C, HERDE K, KIBSCHULL M, WINTERHAGER E, WILLECKE K, GUILLOU F, LÉCUREUIL C, STEGER K, KONRAD L, BIERMANN K, FAILING K, BERMANN M (2007). A Sertoli cell-specific knock- 
out of connexin43 prevents initiation of spermatogenesis. Am J Patho/171:1931.

BUAAS FW, KIRSH AL, SHARMA M, MCLEAN DJ, MORRIS JL, GRISWOLD MD, DE ROOIJ DG, BRAUN RE (2004). PIzf is required in adult male germ cells for stem cell self-renewal. Nat Genet 36: 647-652.

CHABOISSIER MC, KOBAYASHI A, VIDAL VI, LÜTZKENDORF S, VAN DE KANT HJK, WEGNER M, DE ROOIJ DG, BEHRINGER RR, SCHEDL A (2004). Functional analysis of Sox8 and Sox9 during sex determination in the mouse. Development 131: 1891-1901.

CHEN JF, MURCHISON EP, TANG R, CALLIS TE, TATSUGUCHI M, DENG Z, ROJAS M, HAMMOND SM, SCHNEIDER MD, SELZMAN CH, MEISSNER G, PATTERSON C, HANNON GJ, WANG DZ (2008). Targeted deletion of Dicer in the heart leads to dilated cardiomyopathy and heart failure. Proc Natn/ Acad SCl USA 105: 2111-2116.

CHANG H, GAO F, GUILLOU F, TAKETO MM, HUFF V, BEHRINGER RR (2008). Wt1 negatively regulates $\beta$-catenin signaling during testis development. Deve/opment 135: 1875-1885

CHENG AM, BYROM MW, SHELTON J, FORD LP (2005). Antisense inhibition of human miRNAs and indications for an involvement of miRNA in cell growth and apoptosis. Nucleic Acids Res 33: 1290-1297.

COBB BS, NESTEROVA TB, THOMPSON E, HERTWECK A, O'CONNOR E, GODWIN J, WILSON CB, BROCKDORFF N, FISHER AG, SMALE ST, MERKENSCHLAGER M (2005). T cell lineage choice and differentiation in the absence of the RNase III enzyme Dicer. J Exp Med201: 1367-1373.

DECROUY X, GASC JM, POINTIS G, SEGRETAIN D (2004). Functional characterization of $\mathrm{Cx} 43$ based gap junctions during spermatogenesis. J Cell Physiol 200: 146-154.

DE PIETRI TONELLI D, PULVERS JN, HAFFNER C, MURCHISON EP, HANNON GJ, HUTTNER WB (2008). MiRNAs are essential for survival and differentiation of newborn neurons but not for the expansion of neural progenitors during early neurogenesis in the mouse embryonic neocortex. Development 135: 3911 3921.

FILIPPONI D, HOBBS RM, OTTOLENGHI S, ROSSI P, JANNINI EA, PANDOLFI PP, DOLCIS (2007). Repression of kit expression by Plzf in germ cells. Mol Cell Bio/27: 6770-6781.

FUKAGAWA T, NOGAMI M, YOSHIKAWA M, IKENO M, OKAZAKI T, TAKAMI Y NAKAYAMA T, OSHIMURA M (2004). Dicer is essential for formation of the heterochromatin structure in vertebrate cells. Nat Cell Bio/6: 784-791.

GAO F, MAITI S, ALAM N, ZHANG Z, DENG JM, BEHRINGER RR, LÉCUREUIL C, GUILLOU F, HUFF V (2006). The Wilms tumor gene, $W t 1$, is required for Sox9 expression and maintenance of tubular architecture in the developing testis. Proc Natn/ Acad Sci USA 103: 11987-11992.

GONZALEZ-GONZALEZ E, LOPEZ-CASAS PP, DEL MAZO J (2008). The expression patterns of genes involved in the RNAi pathways are tissue-dependent and differ in the germ and somatic cells of mouse testis. Biochim Biophys Acta1779: 306-311.

GOW A, SOUTHWOOD CM, LI JS, PARIALI M, RIORDAN GP, BRODIE SE, DANIAS J, BRONSTEIN JM, KACHAR B, LAZZARINI RA (1999). CNS myelin and sertoli cell tight junction strands are absent in Osp/claudin-11 null mice. Cell 99: 649-659.

HAYASHI K, CHUVA DE SOUSA LOPES SM, KANEDA M, TANG F, HAJKOVA P, LAO K, O'CARROLL D, DAS PP, TARAKHOVSKY A, MISKA EA, SURANI MA (2008). MicroRNA biogenesis is required for mouse primordial germ cell development and spermatogenesis. PLOS One 3: e1738.

HENDZEL MJ, WEI Y, MANCINI MA, VAN HOOSER A, RANALLI T, BRINKLEY BR, BAZETT-JONES DP, ALLIS CD (1997). Mitosis-specific phosphorylation of histone $\mathrm{H} 3$ initiates primarily within pericentromeric heterochromatin during $\mathrm{G} 2$ and spreads in an ordered fashion coincident with mitotic chromosome condensation. Chromosoma 106: 348-360.

KOBAYASHI T, LU J., COBB BS, RODDA SJ, MCMAHON AP, SCHIPANI E, MERKENSCHLAGER M, KRONENBERG HM (2008). Dicer-dependent pathways regulate chondrocyte proliferation and differentiation. Proc Nat/ $\mathrm{Acad} S \mathrm{Cl}$ USA 105: 1949-1954.

LÉCUREUIL C, FONTAINE I, CREPIEUX P, GUILLOU F (2002). Sertoli and granulosa cell-specific Cre recombinase activity in transgenic mice. Genesis
33: $114-118$

LIVAK KJ, SCHMITTGEN TD (2001). Analysis of relative gene expression data using real-time quantitative PCR and the 2(-Delta Delta C(T)) Method. Methods 25: $402-408$

MARCON L, BOISSONNEAULT G (2004). Transient DNA strand breaks during mouse and human spermiogenesis: new insights in stage specificity and link to chromatin remodeling. Biol Reprod 70: 910-918.

MCPHERSON S, LONGO FJ (1993). Chromatin structure-function alterations during mammalian spermatogenesis: DNA nicking and repair in elongating spermatids. Eur J Histochem 37: 109-128.

MENG X, LINDAHL M, HYVÖNEN ME, PARVINEN M, DE ROOIJ DG, HESS MW, RAATIKAINEN-AHOKAS A, SAINIO K, RAUVALA H, LAKSO M, PICHEL JG, WESTPHAL H, SAARMA M, SARIOLA H (2000). Regulation of cell fate decision of undifferentiated spermatogonia by GDNF. Science 287: 1489-1493.

MEYER-FICCA ML, SCHERTHAN H, BÜRKLE A, MEYER RG (2005). Poly(ADPribosyl)ation during chromatin remodeling steps in rat spermiogenesis. Chromosoma 114: 67-74.

MRUK DD, CHENG CY (2004). Sertoli-Sertoli and Sertoli-germ cell interactions and their significance in germ cell movement in the seminiferous epithelium during spermatogenesis. Endocrinol Rev 25: 747-806.

MURCHISON EP, PATRIDGE JF, TAM OH, CHELOUFI S, HANNON GJ (2005). Characterization of Dicer deficient murine embryonic stem cells. Proc Natn/ Acad Sci USA 102: 12135-12140.

PAPAIOANNOU MD, PITETTIJL, RO S, PARK C, AUBRY F, SCHAAD O, VEJNAR CE, KÜHNE F, DESCOMBES P, ZDOBNOV EM, MCMANUS MT, GUILLOU F, HARFE BD, YAN W, JÉGOU B, NEF S (2009). Sertoli cell Dicer is essential for spermatogenesis in mice. Dev Bio/326: 250-259.

PELLEGRINI M, GRIMALDI P, ROSSI P, GEREMIA R, DOLCI S (2003). Developmental expression of BMP4/ALK3/SMAD5 signaling pathway in the mouse testis: a potential role of BMP4 in spermatogonia differentiation. J Cel/ Sci116: 3363-3372.

PELLEGRINI M, FILIPPONI D, GORI M, BARRIOS F, LOLICATO F, GRIMALDI P ROSSI P, JANNINI EA, GEREMIA R, DOLCI S (2008). ATRA and KL promote differentiation toward the meiotic program of male germ cells. Cell Cycle 7: 3878-3888.

RO S, PARK C, SANDERS KM, MCCARREY JR, YAN W (2007). Cloning and expression profiling of testis-expressed microRNAs. Dev Bio/311: 592-602.

SAITOU M, FURUSE M, SASAKI H, SCHULZKE JD, FROMM M, TAKANO H, NODA T, TSUKITA S (2000). Complex phenotype of mice lacking occludin, a component of tight junction strands. Mol Biol Cell 11: 4131-4142.

SEKIDO R, LOVELL-BADGE R (2008). Sex determination involves synergistic action of SRY and SF1 on a specific Sox9 enhancer. Nature 453: 930-934.

SHARPE RM, MCKINNELL C, KIVLIN C, FISHER JS (2003). Proliferation and functional maturation of Sertoli cells, and their relevance to disorders of testis function in adulthood. Reproduction 125: 769-784.

SIMON L, EKMAN GC, TYAGI G, HESS RA, MURPHY KM, COOKE PS (2007). Common and distinct factors regulate expression of mRNA for ETV5 and GDNF, Sertoli cell proteins essential for spermatogonial stem cell maintenance. Exp Cell Res 313: 3090-3099.

SRIDHARAN S, SIMON L, MELING DD, CYR DG, GUTSTEIN DE, FISHMAN GI, GUILLOU F, COOKE, PS (2007). Proliferation of adult sertoli cells following conditional knockout of the Gap junctional protein GJA1 (connexin 43) in mice. Biol Reprod 76: 804-812.

SRINIVAS S, WATANABE T, LIN C, WILLIAM CM, TANABE Y, JESSELL TM, COSTANTINI F (2001). Cre reporter strains produced by targeted insertion of EYFP and ECFP into the ROSA26 locus. BMC Dev Biol1: 4.

STARK A, BRENNECKE J, BUSHATIN, RUSSELL RB, COHEN SM (2005). Animal MicroRNAs confer robustness to gene expression and have a significant impact on 3'UTR evolution. Cell123: 1133-1146.

WILHELM D, PALMER S, KOOPMAN P (2007). Sex determination and gonadal development in mammals. Physiol Rev 87: 1-28.

YAN N, LU Y, SUN H, TAO D, ZHANG S, LIU W, MA Y (2007). A microarray for microRNA profiling in mouse testis tissues. Reproduction 134: 73-79. 


\section{Further Related Reading, published previously in the Int. J. Dev. Biol.}

See Special Issue Pattern Formation edited by Michael K. Richardson and Cheng-Ming Chuong at: http://www.ijdb.ehu.es/web/contents.php?vol=53\&issue =5-6

Gonadal defects in Cited2 -mutant mice indicate a role for SF1 in both testis and ovary differentiation

Alexander N. Combes, Cassy M. Spiller, Vincent R. Harley, Andrew H. Sinclair, Sally L. Dunwoodie, Dagmar Wilhelm and Peter Koopman

Int. J. Dev. Biol. (2010) 54: 683-689 (doi: 10.1387/ijdb.092920ac)

The spatio-temporal pattern of testis organogenesis in mammals - insights from the mole

Francisco D. Carmona, Darío G. Lupiáñez, José-Ezequiel Martín, Miguel Burgos, Rafael Jiménez and Federico Zurita

Int. J. Dev. Biol. (2009) 53: 1035-1044

Aard is specifically up-regulated in Sertoli cells during mouse testis differentiation Terje Svingen, Annemiek Beverdam, Pali Verma, Dagmar Wilhelm and Peter Koopman Int. J. Dev. Biol. (2007) 51: 255-258

Effects of FGF9 on embryonic Sertoli cell proliferation and testicular cord formation in the mouse

Louise Willerton, Robert A. Smith, David Russell and Sarah Mackay

Int. J. Dev. Biol. (2004) 48: 637-643

Abnormal sex-duct development in female moles: the role of anti-Müllerian hormone and testosterone

Federico Zurita, Francisco J Barrionuevo, Philippe Berta, Esperanza Ortega, Miguel Burgos and Rafael Jiménez

Int. J. Dev. Biol. (2003) 47: 451-458

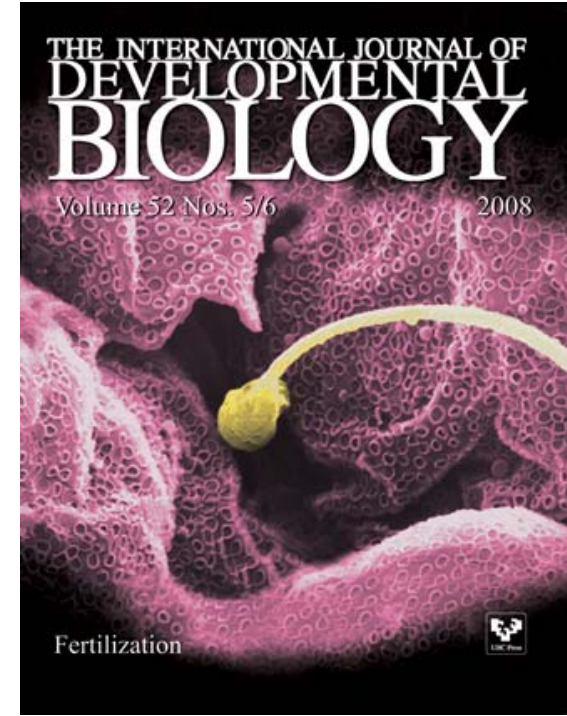

5 yr ISI Impact Factor $(2008)=3.271$

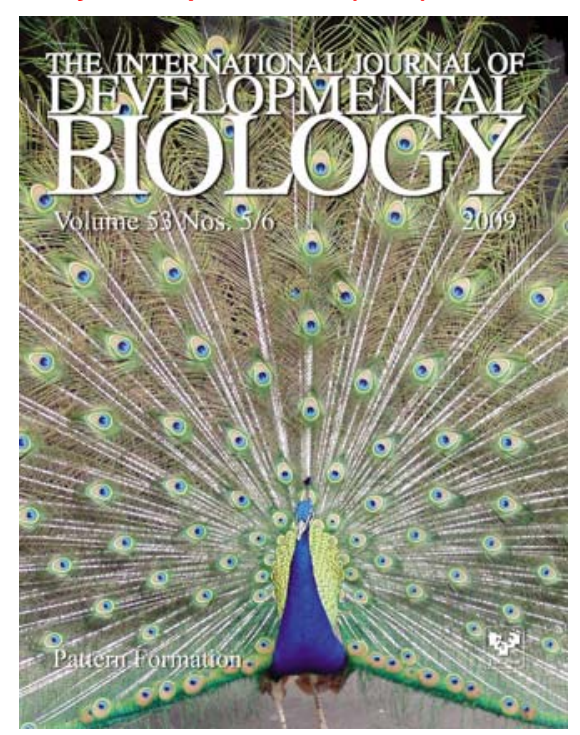

